\title{
The N-terminal extension of S12 influences small ribosomal subunit assembly in Escherichia coli
}

\author{
DEEPIKA CALIDAS, ${ }^{1,2}$ HIRAM LYON, ${ }^{1}$ and GLORIA M. CULVER ${ }^{1,3}$ \\ ${ }^{1}$ Department of Biology, Center for RNA Biology: From Genome to Therapeutics, University of Rochester Medical Center, Rochester, \\ New York 14627, USA
}

\begin{abstract}
The small subunit (SSU) of the ribosome of $E$. coli consists of a core of ribosomal RNA (rRNA) surrounded peripherally by ribosomal proteins (r-proteins). Ten of the 15 universally conserved SSU r-proteins possess nonglobular regions called extensions. The N-terminal noncanonically structured extension of S12 traverses from the solvent to intersubunit surface of the SSU and is followed by a more C-terminal globular region that is adjacent to the decoding center of the SSU. The role of the globular region in maintaining translational fidelity is well characterized, but a role for the S12 extension in SSU structure and function is unknown. We examined the effect of stepwise truncation of the extension of S12 in SSU assembly and function in vitro and in vivo. Examination of in vitro assembly in the presence of sequential $\mathrm{N}$-terminal truncated variants of S12 reveals that N-terminal deletions of greater than nine amino acids exhibit decreased tRNA-binding activity and altered 16S rRNA architecture particularly in the platform of the SSU. While wild-type S12 expressed from a plasmid can rescue a genomic deletion of the essential gene for S12, rpsl; N-terminal deletions of S12 exhibit deleterious phenotypic consequences. Partial $\mathrm{N}$-terminal deletions of $\mathrm{S} 12$ are slow growing and cold sensitive. Strains bearing these truncations as the sole copy of S12 have increased levels of free SSUs and immature 16S rRNA as compared with the wild-type S12. These differences are hallmarks of SSU biogenesis defects, indicating that the extension of S12 plays an important role in SSU assembly.
\end{abstract}

Keywords: ribosome; small subunit; biogenesis; assembly; S12; intrinsically disordered proteins

\section{INTRODUCTION}

Universally conserved small subunit (SSU, 30S) ribosomal protein (r-protein) S12 is composed of two distinct structural elements in all domains of life: an N-terminal nonglobular extension of varying length and sequence, and a conserved C-terminal globular region (see Fig. 1; Smith et al. 2008; Ben-Shem et al. 2010). S12 is essential for growth in organisms ranging from E. coli (Sharma et al. 2007; Shoji et al. 2011 ) to Danio rerio (zebrafish) (Zhang and Lin 2009) and is a key mediator of fidelity of translation in both prokaryotes and eukaryotes (Alksne et al. 1993). Examination of the crystal structure of E. coli SSUs (Schuwirth et al. 2005) reveals that the $\mathrm{N}$-terminus of the protein binds the solvent surface of the SSU, with the extension contacting the rRNA dense regions to end in a C-terminal globular region localized at the intersubunit face of the SSU (see Fig. 1A). The length and localization of the extension as well as hints of its possible functional significance (Agarwal et al. 2011) led us to examine the

\footnotetext{
${ }^{2}$ Present address: Department of Molecular Biology and Genetics, Howard Hughes Medical Institute/Johns Hopkins School of Medicine, Baltimore, MD 21205, USA

${ }^{3}$ Corresponding author

E-mail gloria.culver@rochester.edu

Article published online ahead of print. Article and publication date are at http://www.rnajournal.org/cgi/doi/10.1261/rna.042432.113.
}

role of the extension of S12 in establishing SSU structure during assembly.

The region of the SSU that functions in tRNA binding and decoding lies at the intersection of three structural domains: the body, platform, head, and penultimate and ultimate stems (Woese et al. 1980; Moazed and Noller 1990; Powers and Noller 1991; Alksne et al. 1993; Lee et al. 1997; Lodmell and Dahlberg 1997; Clemons et al. 1999; Yusupov et al. 2001). The localization of the globular region of S12 proximal to the decoding center is unique among SSU r-proteins, and has a well-characterized role in maintaining fidelity of translation (Gorini and Kataja 1964b; Lodmell and Dahlberg 1997; Clemons et al. 1999; Ogle et al. 2002; Schuwirth et al. 2005). Most of the contacts between the N-terminal segment of S12 and 16S rRNA lie within the platform and it also interacts with the body of the 30 S subunit (see Fig. 1A; Allers and Shamoo 2001; Schuwirth et al. 2005). In addition to binding rRNA, the extension also interacts with S8 and S17, and these three r-proteins participate in the assembly of the body,

\footnotetext{
(C) 2014 Calidas et al. This article is distributed exclusively by the RNA Society for the first 12 months after the full-issue publication date (see http://rnajournal.cshlp.org/site/misc/terms.xhtml). After 12 months, it is available under a Creative Commons License (Attribution-NonCommercial 3.0 Unported), as described at http://creativecommons.org/licenses/by-nc/ $3.0 /$.
} 


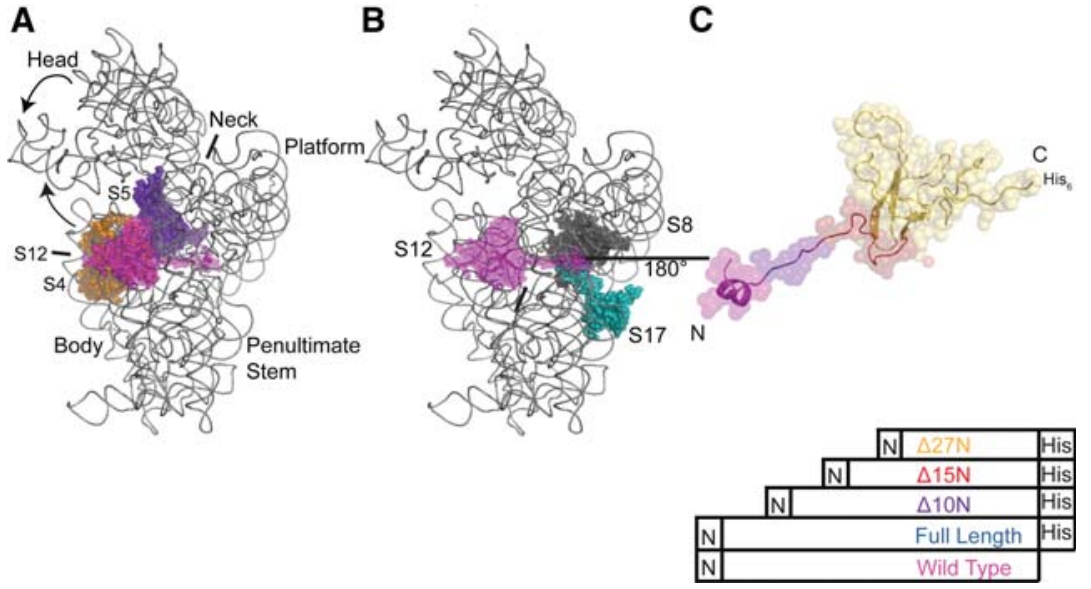

FIGURE 1. Structural relationship of S12 to other SSU components. (A) Positions of S12 (magenta), S4 (orange), and S5 (violet) in the three-dimensional structure of the E. coli 30S subunit. $16 \mathrm{~S}$ rRNA is gray and other r-proteins omitted for clarity. All figures containing three-dimensional structures were prepared using PyMOL and Protein Data Bank file 2AW7 (Schuwirth et al. 2005). (B) Location of S12 (magenta), S8 (black), and S17 (teal) in the three-dimensional structure of the $30 \mathrm{~S}$ subunit. $16 \mathrm{~S}$ rRNA is gray and other r-proteins omitted for clarity. $(C)$ Three-dimensional structure of $S 12$ as found in the $30 \mathrm{~S}$ subunit, rotated $180^{\circ}$ with respect to $B$, with the variants color coded. S12WT is magenta, S12Full Length is blue, $\mathrm{S} 12 \Delta 10 \mathrm{~N}$ is purple, $\mathrm{S} 12 \Delta 15 \mathrm{~N}$ is red, and $\mathrm{S} 12 \triangle 27 \mathrm{~N}$ is orange.

shoulder, and platform of the SSU (see Fig. 1B; Stern et al. 1988a,b; Svensson et al. 1988; Schuwirth et al. 2005; Calidas and Culver 2011). Little is known of the role of the extension in the structure and function of the SSU. The widespread contacts made by the extension with $16 \mathrm{~S}$ rRNA and other r-proteins led us to hypothesize that it plays a role in aligning distant structural elements of the SSU.

More than one-third of all r-proteins possess extensions (Brodersen et al. 2002; Schuwirth et al. 2005) and it has been hypothesized that extensions scaffold tertiary structure (Ban et al. 2000; Wimberly et al. 2000; Wilson and Nierhaus 2005). However, the exact role of the extensions in bacterial ribosome function and assembly is unclear. Of the r-proteins with extensions that have been studied, complete truncation of the extension of E. coli L20 has the most profound effect, leading to a dominant lethal phenotype, while partial deletions resulted in slow growth due to defects in large subunit (LSU or 50S) assembly (Guillier et al. 2005). In contrast, deletion of the long loops of E. coli L4 and L22 had no effect on the assembly of the $50 \mathrm{~S}$ subunit (Zengel et al. 2003). In yeast, mutations in the C-terminal extension of r-protein S14, a homolog of bacterial r-protein S11 blocked maturation of precursor SSU particles (Jakovljevic et al. 2004). Thus, a common role and significance of r-protein extensions in ribosomal subunit biogenesis and function remains unclear.

In this work we examined the role of the extension of S12 in SSU assembly and function in vitro and in vivo. We created multiple truncations of the extension of S12 starting from the N-terminus (Figs. 1C, 4A, below): truncation within the two-turn helix $(\mathrm{S} 12 \Delta 6 \mathrm{~N})$, truncation past the two turn helix $(\mathrm{S} 12 \Delta 10 \mathrm{~N}, \mathrm{~S} 12 \Delta 11 \mathrm{~N})$, truncation of half the extension
$(\mathrm{S} 12 \Delta 15 \mathrm{~N})$, truncation of three-fourths of the extension $(\mathrm{S} 12 \Delta 24 \mathrm{~N})$, and truncation of the entire extension $(\mathrm{S} 12 \Delta 27 \mathrm{~N})$. SSUs reconstituted in vitro with the full complement of recombinant r-proteins and different S12 variants exhibited diminishing functionality with a decrease in length of the extension (Fig. 2). In addition, minimal ribonucleoprotein particles (RNPs) reconstituted in vitro in the presence of $\mathrm{S} 12 \triangle 15 \mathrm{~N}$ and $\mathrm{S} 12 \Delta 27 \mathrm{~N}$ show altered structure of $16 \mathrm{~S}$ rRNA when compared with RNPs containing full-length S12, notably in the vicinity of the central pseudoknot (Fig. 3). Thus, truncation of the extension alters SSU structure and function in vitro.

We further examined whether the extension played a role in SSU assembly in vivo. As the gene encoding S12 ( $r p s L)$ is essential (Sharma et al. 2007; Shoji et al. 2011), we used a genomic deletion strain ( $\triangle r p s l \mathrm{pSTR}$ ) whose viability is dependent upon plasmid expression of wild-type S12 (pSTR). The wild-type plasmid was then replaced by plasmids expressing S12 variants (pS12 $\Delta 6 \mathrm{~N}, \mathrm{pS} 12 \Delta 11 \mathrm{~N}$, pS12 $\Delta 15 \mathrm{~N}, \mathrm{pS} 12 \Delta 24 \mathrm{~N}$ ) by plasmid shuffle to create $\Delta r p s l$ pS12 $\triangle 6 \mathrm{~N}, \Delta r p s l \mathrm{pS} 12 \Delta 11 \mathrm{~N}$, and $\Delta r p s l \mathrm{pS} 12 \Delta 15 \mathrm{~N}$ (Fig. $4 \mathrm{~A}$ ). Diminution of the N-terminal segment correlated with increasing growth defects and subunit profile abnormalities (Figs. 4B,C, 5A,B). Precursor 16S rRNA (17S rRNA) is observed in SSU fractions from the $\Delta r p s l$ pS12 $\Delta 15 \mathrm{~N}$ strain, also to a lesser degree in $\Delta r p s l$ pS12 $\Delta 6 \mathrm{~N}$ and $\Delta r p s l \mathrm{pS} 12 \Delta 11 \mathrm{~N}$ (Fig. $5 \mathrm{C}$ ). Data from both in vitro and in vivo studies suggest that the N-terminal extension of S12 plays a critical role in

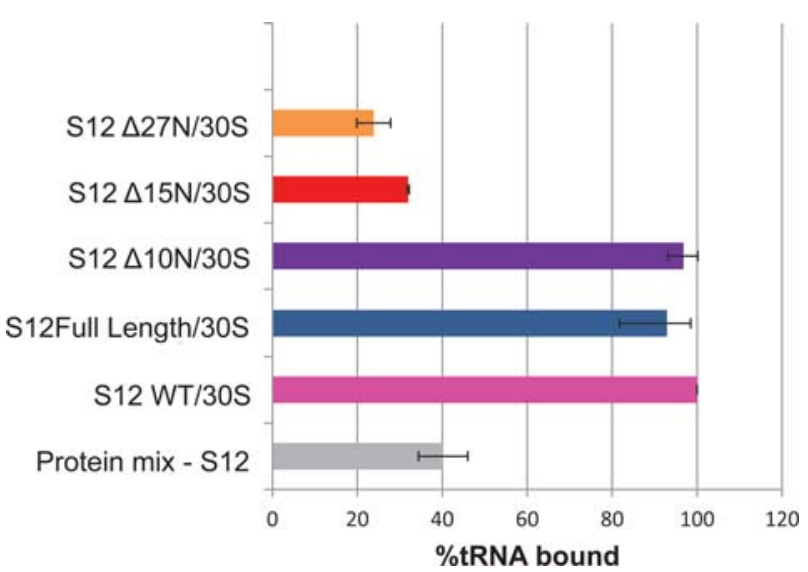

FIGURE 2. Analysis of the effect of truncation of S12's extension in vitro. Truncation of the extension by more than 10 amino acids affects the function of $30 \mathrm{~S}$ particles in vitro. Activity of particles is measured by the ability to bind labeled tRNA. Results were normalized to tRNA binding by $30 \mathrm{~S}$ subunits reconstituted with S12WT. 


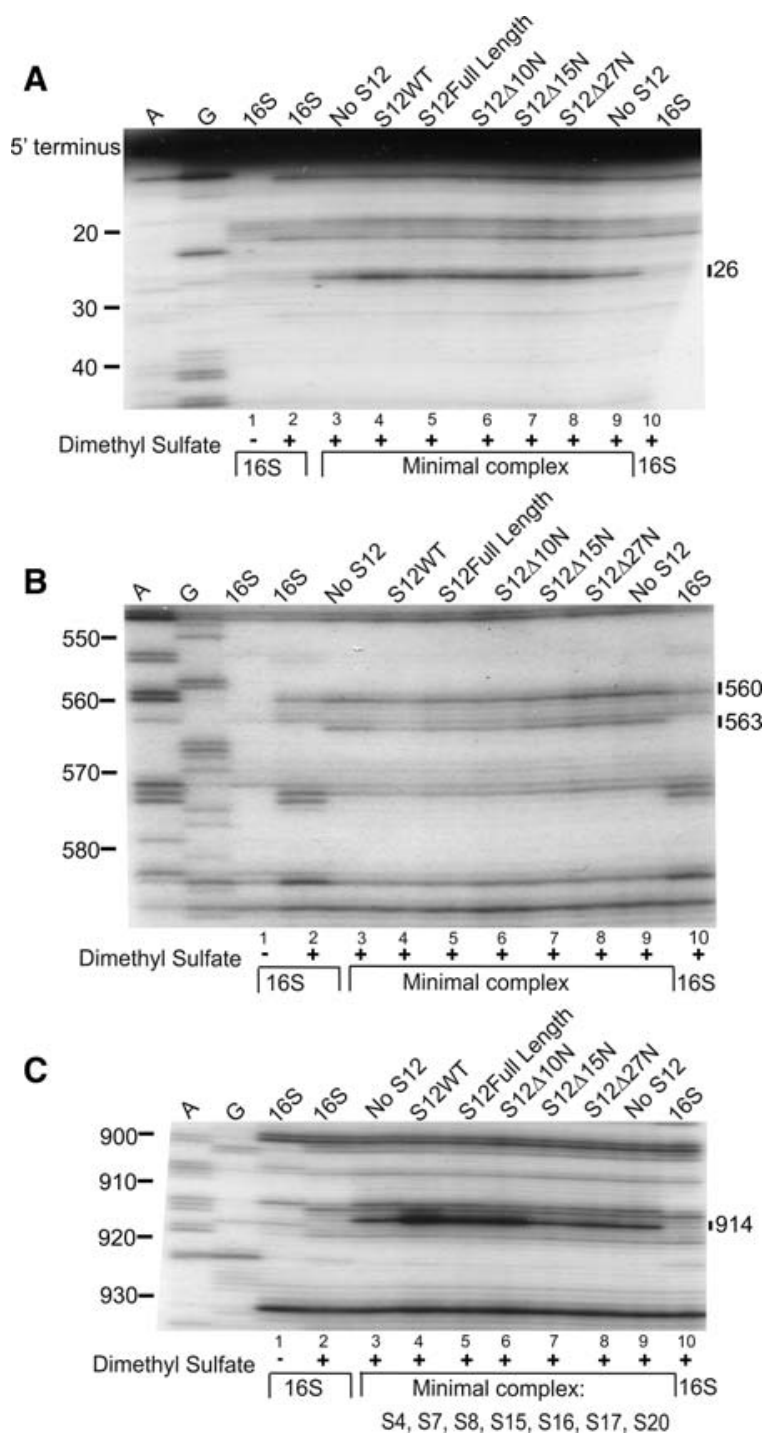

FIGURE 3. Primer extension analysis of RNPs containing S12 variants. Sequencing gel of 16S rRNA in the following reactions: untreated 16S rRNA (lane 1); dimethyl sulfate treated 16S rRNA (lanes 2,10); dimethyl sulfate-treated minimal complex (S4, S7, S8, S15, S16, S17, S20, $16 \mathrm{~S}$ rRNA) (lanes 3,9); dimethyl sulfate-treated minimal complex with S12WT (lane 4), S12 full-length (lane 5), S12 $\Delta 10 \mathrm{~N}$ (lane 6), S12 $\Delta 15 \mathrm{~N}$ (lane 7 ), and $\mathrm{S} 12 \triangle 27 \mathrm{~N}$ (lane 8 ). A and G are sequencing lanes. Bars indicate changes in methylation patterns compared with complexes lacking S12 (lanes 3,9). The primers utilized in $A, B$, and $C$ are 232, 683, and 1046, respectively.

assembly of E. coli SSUs and indicates that r-protein extensions can greatly alter rRNA maturation and architecture.

\section{RESULTS}

\section{The N-terminal extension of S12 plays a role in SSU tRNA binding in vitro}

We wished to determine whether the extension of S12 modulates SSU formation, its function, and $16 \mathrm{~S}$ rRNA folding. To achieve this end, we generated a series of $\mathrm{N}$-terminal truncations of S12. Four different C-terminal His-tagged constructs were made for overexpression and purification (S12Full Length, S12 $\Delta 10 \mathrm{~N}, \mathrm{~S} 12 \Delta 15 \mathrm{~N}$, and S12 $\Delta 27 \mathrm{~N}$ ) (Fig. 1C). The C-terminal His-tag was included to aid in purification of the mutant proteins from possible contamination with endogenous wild-type S12. Wild-type untagged (S12WT) S12 was used as a control to monitor whether the C-terminal His-tag altered S12 function. The overexpressed, purified S12 variants were then assembled with $16 \mathrm{~S}$ rRNA in the presence of different r-proteins to examine the role of S12 in assembly and function of the $30 \mathrm{~S}$ subunit in vitro.

Functional, active SSUs bind tRNAs in an message-dependent manner in vitro making this is an ideal assay to assess the activity of SSUs reconstituted with S12 variants (Fig. 2). In this assay, labeled tRNA is supplied in excess, so that each tRNA-binding site of the SSU should be saturated. S12WT, S12Full Length, and truncated proteins

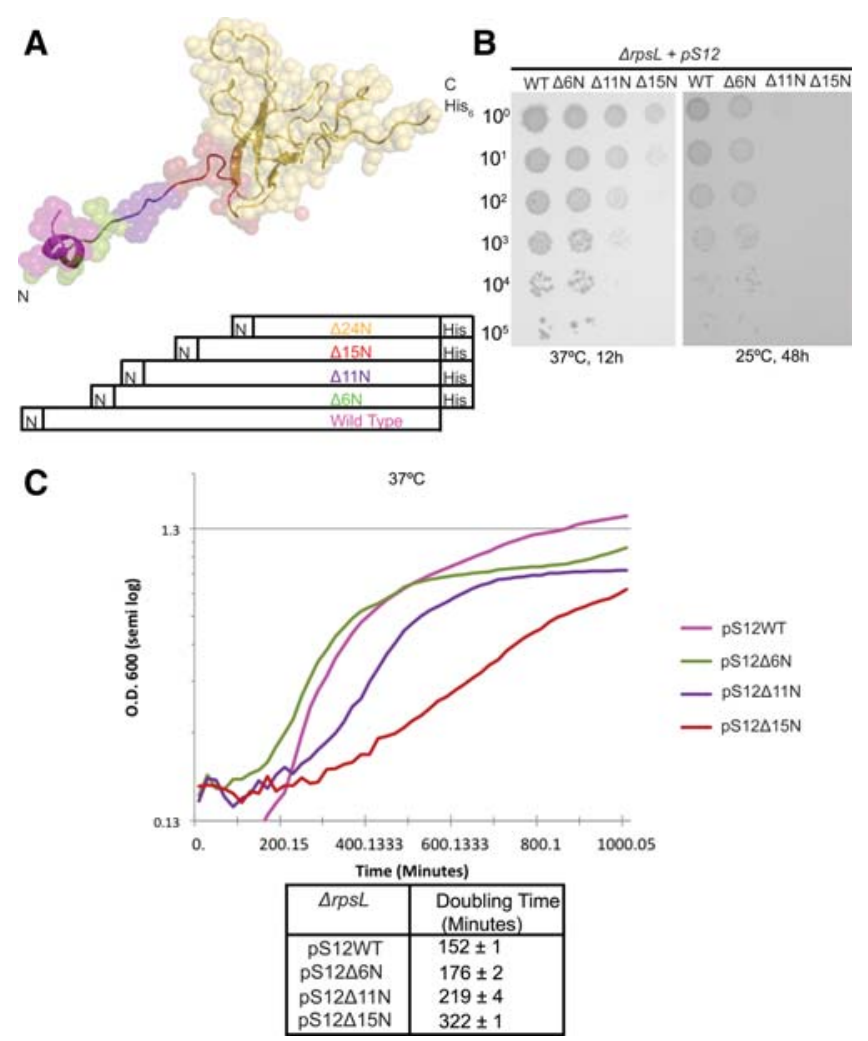

FIGURE 4. In vivo analysis of strains bearing truncations of S12. (A) Three-dimensional structure of S12 as found in the 30S subunit, with the positions of truncations color coded as in Figure 2, except that $S 12 \triangle 6 \mathrm{~N}$ is green. $(B)$ Serial dilution analysis of the growth of $\Delta r p s l$ strains dependent upon WT and truncated proteins at $37^{\circ} \mathrm{C}$ and $25^{\circ} \mathrm{C}$. Overnight cultures were diluted to equal $\mathrm{OD}_{600}$ and then serially diluted by 10 -fold increments. These were spotted on LB supplemented with kanamycin $(50 \mu \mathrm{g} / \mathrm{mL})$, ampicillin $(100 \mu \mathrm{g} / \mathrm{mL})$, and arabinose $(0.2 \%)$. (C) Growth of $\Delta r p s l$ strains in liquid media was measured in a Bioscreen automatic growth analyzer (Growth Curves) and plotted on a semi-log plot. Doubling times are presented in tabular form. 

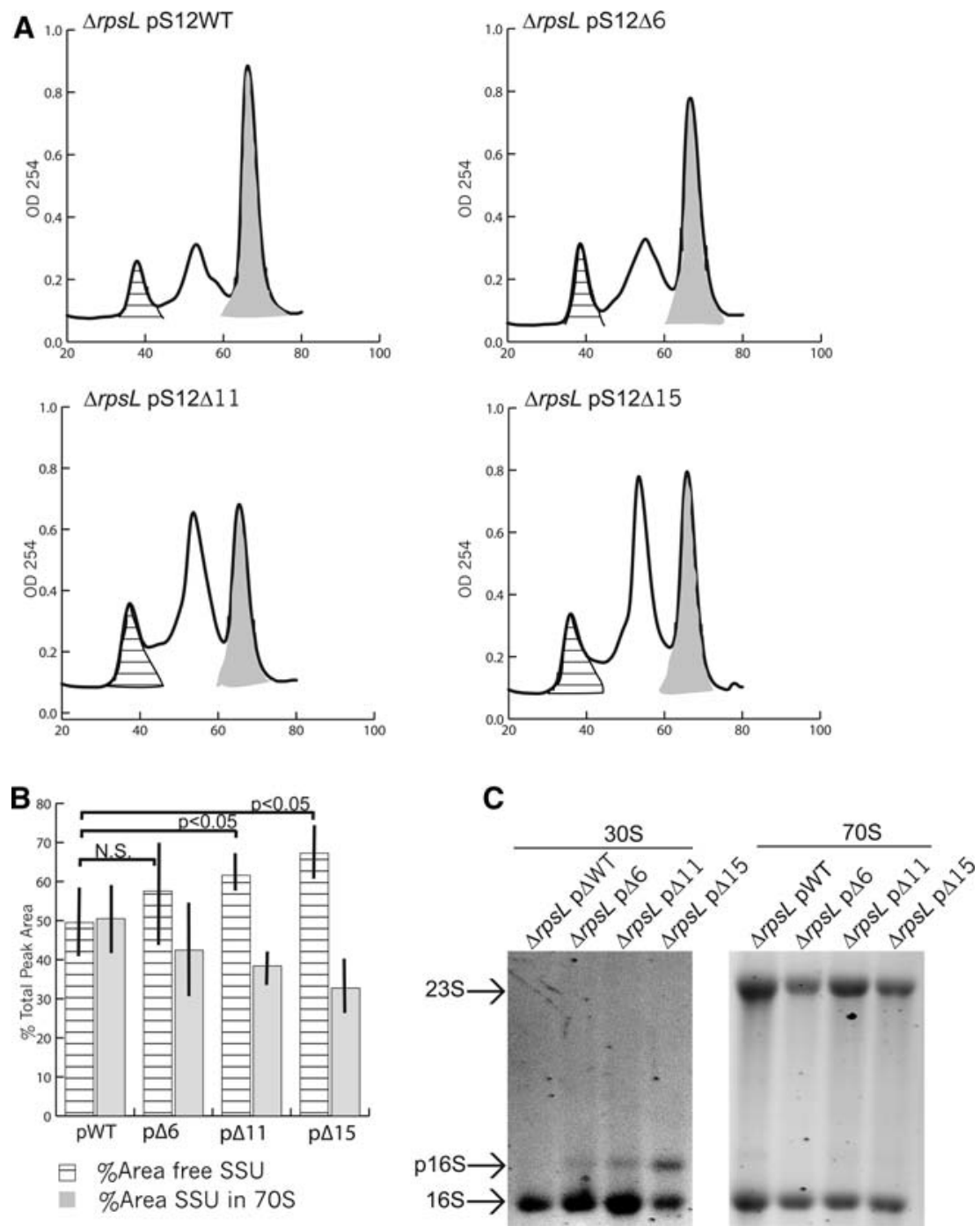

FIGURE 5. In vivo analysis of ribosomes formed in strains bearing truncations of S12. $(A)$ Representative sucrose gradient sedimentation profiles of ribosomal subunits from $\Delta r p s l$ strains bearing pS12WT or pS12 $\triangle \mathrm{XN}$. The $10 \%-40 \%$ gradients were pumped from the top to the bottom using a Biocomp Piston Gradient Fractionator and elution of the small and large subunits followed by $70 \mathrm{~S}$ ribosomes was detected by monitoring at $\mathrm{OD}_{254}$. Area under the curve was calculated from the cross-hatched (free SSU) and gray-shaded regions (70S) in each profile. (B) Comparison between strains of percent area occupied by free subunits (cross-hatched) and subunits within ribosomes (gray) is represented by a bar graph. $(C)$ Agarose gel analysis of RNA content of free SSUs and ribosomes.

$(\mathrm{S} 12 \Delta 10 \mathrm{~N}, \mathrm{~S} 12 \Delta 15 \mathrm{~N}$, and $\mathrm{S} 12 \Delta 27 \mathrm{~N})$ were reconstituted with the remaining SSU r-proteins and 16S rRNA (S12WT/ $30 S$, S12Full Length/30S, S12 $\Delta 10 \mathrm{~N} / 30 S, S 12 \Delta 15 \mathrm{~N} / 30 \mathrm{~S}$, S12 $27 \mathrm{~N} / 30 \mathrm{~S})$. S12WT/30S and S12Full Length/30S have comparable binding activity, demonstrating that the C-terminal tag does not affect S12 activity or the incorporation of the resulting SSU. Complexes assembled with $S 12 \triangle 10 \mathrm{~N}$ also bind tRNA comparable to S12WT/30S and S12Full Length/30S. On the other hand, $S 12 \Delta 15 \mathrm{~N} / 30 \mathrm{~S}$ and $\mathrm{S} 12 \Delta 27 \mathrm{~N} / 30 \mathrm{~S}$ are as deficient at binding tRNA as RNPs reconstituted in the absence of S12 (Protein mix-S12). This change in functional capacity could result from reduced incorporation of shorter S12 into RNPs and/or the improper assembly or folding of particles when the extension is reduced in length by half or more.

\section{N-terminal truncation of S12 results in changes in $16 \mathrm{~S}$ rRNA conformation}

Given differences in function of 30 S subunits with different S12 constructs, we next examined the effect of the truncation of S12 on the architecture of 16S rRNA using chemical probing and primer extension. Differences in $16 \mathrm{~S}$ rRNA reactivity were observed when S12 was added in vitro to complexes containing $16 \mathrm{~S}$ rRNA and early binding r-proteins S4, S7, S8, S15, S16 S17, and S20 (Stern et al. 1988b); however, upon addition of later binding r-proteins to these complexes, the changes attributed to S12 are no longer observed. Thus, probing of these minimal complexes (16S rRNA and S4, S7, S8, S15, S16 S17, and S20) \pm S12 allows structural changes associated with $\mathrm{S} 12$ binding to be examined. RNPs were assembled with minimal complex and different variants of S12 (WT, Full-Length, $\Delta 10 \mathrm{~N}$, $\Delta 15 \mathrm{~N}$, and $\Delta 27 \mathrm{~N}$ ), subsequently probed with dimethyl sulfate, and 16S rRNA was analyzed by primer extension.

Addition of S12WT to the minimal complex (Fig. 3A, cf. lanes 3,9 with lane 4) results in an enhancement of the reactivity of A26, proximal to the $5^{\prime}$ terminus of $16 \mathrm{~S}$ rRNA as previously observed (Stern et al. 1988b). Similar levels of enhancement are observed upon addition of S12Full-Length, S12 $\Delta 10 \mathrm{~N}, \mathrm{~S} 12 \Delta 15 \mathrm{~N}$, and $S 12 \triangle 27 \mathrm{~N}$ (Fig. 3A, lanes 5,6,7,8, respectively). This suggests that truncation of the N-terminal region does not cause global misfolding of the entire population of protein molecules or complete inability of these variants to associate with $16 \mathrm{~S}$ rRNA. In contrast, within the central domain, at residues A560 and A563 (Fig. 3B), the protection observed upon addition of S12WT (Fig. 3B, lane 4) or S12Full-Length (Fig. 3B, lane 5 ), is reduced upon truncation of the protein by 10 amino acids (Fig. 3B, lane 6) and is absent upon further truncation (Fig. 3B, lanes 7,8). Indeed, in the presence of $S 12 \Delta 15 \mathrm{~N}$ (Fig. 3B, lane 7) or S12 $\triangle 27 \mathrm{~N}$ (Fig. 3B, lane 8) the pattern appears to revert back to that seen in the absence of S12 (Fig. 3B, lanes 3,9; Stern et al. 1988b). Analysis of contacts between S12 and 16S rRNA in the crystal structure of the 30S subunit indicates that the loss of protection at nucleotide 
563 is most likely due to deletion of residue 11 of the protein (Fig. 6D-F).

Addition of S12WT (Fig. 3C, lane 4) to the minimal complex (Fig. 3C, lanes 3,9) enhances the reactivity of A914, and this change is observed to a lesser extent upon incorporation of both S12Full-Length (Fig. 3C, lane 5) and S12 $\triangle 10 \mathrm{~N}$ (Fig. 3C, lane 6). Truncation of the extension by 15 amino acids (Fig. 3C, lane 7) or more (Fig. 3C, lane 8) abolishes this change in reactivity, indicating that the conformation of $16 \mathrm{~S}$ rRNA is more similar to that seen in the absence of S12.

Our results indicate that truncation of the $\mathrm{N}$-terminus of S12 by 10 amino acids or more does not abolish contact between the globular region of S12 and 16S rRNA. However, a change is observed that correlates with loss of a direct contact between the N-terminal extension and nucleotide A563. The changes in reactivity at nucleotides A560 and A914 are more likely due to long-range structural changes associated with the absence of the $\mathrm{N}$-terminus of $\mathrm{S} 12$. These findings are consistent with the $\mathrm{N}$-terminal extension of $\mathrm{S} 12$ playing a role in shaping the architecture of the assembling SSUs by orchestrating changes in both proximal and distant structural elements.

\section{The $\mathrm{N}$-terminal extension of $\mathrm{S} 12$ plays a role in vivo}

The gene encoding S12 ( $r p s L)$ is essential in E. coli (Sharma et al. 2007; Shoji et al. 2011). Therefore, to analyze the effect of changes in the N-terminus of S12 we used a genomic deletion of $r p s L$ ( $\triangle r p s L \mathrm{pSTR}$ ) where growth is supported by expression of S12 from a covering plasmid (pSTR) (Link et al. 1997; Sharma et al. 2007). Plasmid shuffle with negative selection was used to introduce plasmids expressing S12WT, $\mathrm{S} 12 \Delta 6 \mathrm{~N}, \quad \mathrm{~S} 12 \Delta 11 \mathrm{~N}, \quad \mathrm{~S} 12 \Delta 15 \mathrm{~N}$, and S12 $\triangle 24 \mathrm{~N}$ (Fig. $4 \mathrm{~A}$ ) under the control of an inducible promoter (Shoji et al. 2011). We generated four strains using this technique: $\triangle r p s L \mathrm{pS} 12 \mathrm{WT}, \triangle r p s L$ $\mathrm{pS} 12 \Delta 6 \mathrm{~N}, \Delta r p s L \mathrm{pS} 12 \Delta 11 \mathrm{~N}$, and $\Delta r p s L$ pS12 $\triangle 15 \mathrm{~N}$. To aid in plasmid shuffle, a specific plasmid for expression of the truncated S12 proteins was used that simultaneously allowed negative selection of the full-length $r p s L$ gene and S12 mutant expression (Link et al. 1997). As a consequence, the set of truncation mutants is as similar as possible, but not identical, to those S12 truncations studied in vitro. Despite multiple efforts and reoptimized conditions, we were unable to generate $\Delta r p s L \mathrm{pS} 12 \Delta 24 \mathrm{~N}$, leading us to speculate that the presence of some amino acids between residues 15 and 24 of S12 are necessary for cellular viability.

The growth of strains dependent on wild-type and truncated forms of S12 was examined on plates (Fig. 4B) and in liquid media (Fig. 4C). In both conditions, it is clear that truncation of S12 by more than six amino acids at its N-terminus is deleterious to cell growth even at the optimum growth temperature $\left(37^{\circ}\right.$ $\mathrm{C})$; truncation of three-fourths of the extension of S12 $(\mathrm{S} 12 \Delta 24 \mathrm{~N})$ does not appear to support growth. Also, strains dependent on truncated forms of $\mathrm{S} 12$ $(\Delta r p s L \mathrm{pS} 12 \Delta 6 \mathrm{~N}, \Delta r p s L \mathrm{pS} 12 \Delta 11 \mathrm{~N}$, and
FIGURE 6. Modification data from Figure 3 mapped as spheres on the three-dimensional structure of the $30 \mathrm{~S}$ ribosomal subunit. $16 \mathrm{~S}$ rRNA is gray, the various $\mathrm{S} 12$ variants are color coded as in Figure 2, and other r-proteins are omitted for clarity. (A) S12WT and 16S rRNA in the 30S subunit. $(B-F)$ Data from complexes containing S12WT, S12Full-Length, S12 $\Delta 10 \mathrm{~N}, \mathrm{~S} 12 \Delta 15 \mathrm{~N}$, and $\mathrm{S} 12 \triangle 27 \mathrm{~N}$ plotted as spheres on $16 \mathrm{~S}$ rRNA. Black spheres indicate nucleotides protected upon ad dition of S12WT, while green spheres indicate positions of enhancement of reactivity. Strength of modification is represented by the size of the sphere. The view is rotated $180^{\circ}$ and zoomed in for greater clarity. 
$\Delta r p s L \mathrm{pS} 12 \Delta 15 \mathrm{~N}$ ) exhibit cold sensitivity (Fig. 4B), a hallmark of ribosome biogenesis defects.

This is consistent with data from the initial plasmid shuffle to generate the strains. The success rate of each shuffle was defined as the percent colonies observed after shuffling in plasmids expressing S12 variants (pS12WT, pS12 $\Delta 6 \mathrm{~N}$, $\mathrm{pS} 12 \Delta 11 \mathrm{~N}, \mathrm{pS} 12 \Delta 15 \mathrm{~N}$, and $\mathrm{pS} 12 \Delta 24 \mathrm{~N}$ ) that were phenotypically consistent with the loss of the first plasmid (pSTR). We had an average success rate (out of four experiments) of $100 \%$ for $\Delta r p s L$ pS12WT, $86 \%$ for $\Delta r p s L$ pS12 $\Delta 6 \mathrm{~N}, 83 \%$ for $\Delta r p s L \mathrm{pS} 12 \Delta 11 \mathrm{~N}, 36 \%$ for $\Delta r p s L \mathrm{pS} 12 \Delta 15 \mathrm{~N}$, and $0 \%$ for $\Delta r p s L \mathrm{pS} 12 \Delta 24 \mathrm{~N}$ (data not shown).

At $37^{\circ} \mathrm{C}, \Delta r p s L \mathrm{pS} 12 \mathrm{WT}$ and $\Delta r p s L \mathrm{pS} 12 \Delta 6$ exhibit similar growth properties (Fig. 4B,C) consistent with in vitro analysis indicating that deletion of up to 10 amino acids at the $\mathrm{N}$ terminus does not affect assembly significantly. $\Delta r p s L$ $\mathrm{pS} 12 \Delta 11 \mathrm{~N}$ and $\triangle r p s L \mathrm{pS} 12 \Delta 15 \mathrm{~N}$ demonstrate increased doubling and lag times in liquid culture (Fig. 4C). Expression of $\mathrm{S} 12 \Delta 6 \mathrm{~N}, \mathrm{~S} 12 \Delta 11 \mathrm{~N}, \mathrm{~S} 12 \Delta 15 \mathrm{~N}$, and $\mathrm{S} 12 \Delta 24 \mathrm{~N}$ in a wild-type background had no significant effect on growth (data not shown). Therefore, the mutant proteins are likely not dominant, although the stability and expression of each variant is unknown. In conclusion, truncation of half or more of the extension has deleterious effects on the growth of the cell, especially at low temperatures, suggesting a role for the $\mathrm{N}$-terminal extension of S12 in SSU biogenesis.

\section{Truncation of the N-terminus of S12 alters ribosome profiles}

One explanation for the growth defects observed in $\Delta r p s L$ $\mathrm{pS} 12 \Delta 11 \mathrm{~N}$ and $\Delta r p s L \mathrm{pS} 12 \Delta 15 \mathrm{~N}$ as well as the lethal phenotype conferred by $\Delta r p s L \mathrm{pS} 12 \Delta 24 \mathrm{~N}$ is improper SSU assembly. Consequently, we examined the sucrose gradient sedimentation profiles of free subunits and ribosomes in all strains $(\Delta r p s L \mathrm{pS} 12 \mathrm{WT}, \Delta r p s L \mathrm{pS} 12 \Delta 6 \mathrm{~N}, \Delta r p s L \mathrm{pS} 12 \Delta 11 \mathrm{~N}$, and $\Delta r p s L \mathrm{pS} 12 \Delta 15 \mathrm{~N}$ ) at $37^{\circ} \mathrm{C}$ (Fig. $5 \mathrm{~A}$ ). There is no significant change in the percent area of free SSUs upon comparing $\triangle r p s L \mathrm{pS} 12 \mathrm{WT}$ and $\triangle r p s L \mathrm{pS} 12 \triangle 6 \mathrm{~N}(P=0.34)$ (Fig. 5A,B). There is a significant increase in free SSUs in $\triangle r p s L$ $\mathrm{pS} 12 \Delta 11 \mathrm{~N}(P=0.03)$ and $\Delta r p s L \mathrm{pS} 12 \Delta 15 \mathrm{~N} \quad(P=0.013)$ strains compared with the wild-type $S 12$ control strain (Fig. $5 \mathrm{~A}, \mathrm{~B})$. Thus, these SSUs appear to be somewhat defective in subunit association, strongly suggesting a defect in initiation and/or biogenesis. Consistent with the latter hypothesis, we observe presence of precursor $16 \mathrm{~S}$ rRNA ( $16 \mathrm{~S}$ rRNA) in free SSUs from various $r p s L$ truncation strains (Fig. 5C). To summarize, there is a strong correlation between changes in growth, changes in ratio of free SSUs to ribosomes, presence of p16S rRNA, and increasing truncation of S12.

\section{DISCUSSION}

We created partially overlapping subsets of $\mathrm{N}$-terminal truncation mutants of S12 to analyze the role of the noncanoni- cally structured segment, both in vitro and in vivo (Figs. 1C, 4A). Changes in tRNA binding and architecture of $16 \mathrm{~S}$ rRNA were observed in vitro when the length of the N-terminal extension of S12 was reduced by half or more. In vivo truncation of the N-terminus of S12 can change growth at normal and cold temperatures, the ratio of free SSUs to $70 \mathrm{~S}$ ribosomes, and 16S rRNA maturation. These data suggest a critical role of the $\mathrm{N}$-terminal extension of S12 in SSU biogenesis and function.

In vitro analyses offer initial information for a role of the $\mathrm{N}$-terminal segment of $\mathrm{S} 12$ in $30 \mathrm{~S}$ subunit function and structuring the SSU platform. Truncation of the extension by half or more $(\mathrm{S} 12 \Delta 15 \mathrm{~N}$ and $\mathrm{S} 12 \Delta 27 \mathrm{~N})$ caused a marked reduction in the ability of RNPs to bind tRNA and the reduction resulted in binding data comparable to particles lacking S12 (Fig. 2). However, it is unlikely that this is due to a failure of truncated S12 to incorporate into SSUs as probing data reveal a reactivity change in $16 \mathrm{~S}$ rRNA residues that are correlated with S12WT association (Figs. 3A, 6). Moreover, this change can be attributed to its globular region, indicating that absence of the extension does not cause global unfolding of S12 and that these deletions do assemble into RNPs. However, we did observe changes in reactivity in other regions of 16S rRNA associated with systematic truncation of S12. For example, the loss of protection at $\mathrm{A} 563$ could be directly attributed to truncating S12 past amino acid 11 (Figs. 3B, 6E), as Arginine 11 interacts with A563 in SSUs (see Fig. 6D). Our previous work suggested that alternative conformations of $16 \mathrm{~S}$ rRNA existed at nucleotides 566-568 in a minimal complex lacking all $5^{\prime}$ domain binding proteins and that the N-terminal segment of S12 played a role in assembly of the interdomain region between the SSU body and platform (Calidas and Culver 2011). In addition to this direct effect, upon deletion of the $\mathrm{N}$-terminus of S12, differences in reactivity have been observed that are distal to S12 in SSUs (see Fig. 6). Nucleotides 560 and 914 exhibit differential reactivity in the presence of $S 12 \Delta 15 \mathrm{~N}$ and S12 $27 \mathrm{~N}$ (Figs. 3B,C, 6E,F) as compared with S12Full Length (Figs. 3C, lane 5, 6C) or S12 $\triangle 10 \mathrm{~N}$ (Figs. 3C, lane 6, $6 \mathrm{D})$. Changes in $16 \mathrm{~S}$ rRNA architecture associated with truncation of S12 appear to be attributable to both direct and longrange effects. Since the main aim of this publication is to determine the role of the extension of S12 in stabilizing 16S rRNA architecture, this work has been carried out on minimal particles. It is possible that the changes in $16 \mathrm{~S}$ rRNA architecture might affect $r$-proteins binding other regions of the particle; however, it is striking that no reactivity differences were observed in regions directly associated with translational fidelity. This is consistent with the vast majority of fidelity mutations mapping to the globular region of S12 (Gorini and Kataja 1964a; Sharma et al. 2007; Agarwal et al. 2011). Our probing experiments indicate that the $\mathrm{S} 12$ protein variants bind to $16 \mathrm{~S}$ rRNA (at least minimally), and changes are consistent with previous structural (Schuwirth et al. 2005), probing (Stern et al. 1988b), and assembly (Powers and Noller 1995; Talkington et al. 2005; Adilakshmi et al. 2008) data. 
After plasmid shuffle, such that the cloned truncations were the sole source of S12 in vivo, three major changes could be observed. First, growth defects were observed with all tested strains expressing truncated S12 (Fig. 4B,C). The changes were exacerbated at low temperature and with decreasing length of the N-terminal segment, such that deletion of Nterminal 15 amino acids affected growth more than deletion of 11 amino acids, which grew more slowly than the variant lacking six residues. Moreover, we were unable to obtain colonies expressing deletions of 24 amino acids. Thus, the Nterminal extension of S12 likely contributes to the essential role of S12. In contrast, we see no significant changes in growth in the presence of antibiotics that alter decoding (data not shown), implying that the $\mathrm{N}$-terminus of S12 plays a predominant role in SSU assembly. Second, we observe that upon truncation of half the extension in vivo, there is a significant increase in the population of free SSUs (Fig. 5A,B). This phenotype is similar to that observed upon mutation of the C-terminal extension of yeast S14, which results in an accumulation of $20 \mathrm{~S}$ pre rRNA in $43 \mathrm{~S}$ pre-ribosomes (Jakovljevic et al. 2004). Finally, we observed an increase in p16S rRNA in strains bearing truncated variants of S12. In E. coli, an increase in free SSUs associated with p16S rRNA has been found in strains with perturbed ribosome biogenesis cascades such as era-depleted cells, $\Delta y j e Q$ and $\Delta k s g A$ (Inoue et al. 2003; Campbell and Brown 2008; Connolly et al. 2008). Changes in growth and aberrant subunit/ribosome ratios as well as increased p16S rRNA content strongly implies a role for the extension of S12 in SSU biogenesis.

While it would have been ideal to directly compare the same truncated S12 proteins in vitro and in vivo, this was complicated by the requirement that the plasmid allowing expression of the truncated $r p s L$ gene also encode a gene that allows for selection against the plasmid expressing wildtype full-length $r p s L$. This compromise allowed the most similar comparison while ensuring that possible wild-type S12 expression was minimized. While our in vivo and in vitro data are in general agreement, there is a difference in the phenotype observed in vivo for the $\Delta r p s L \mathrm{pS} 12 \Delta 11 \mathrm{~N}$ strain and the in vitro data from $S 12 \Delta 10 \mathrm{~N}$. While in vitro-formed particles incorporating $S 12 \Delta 10 \mathrm{~N}$ have tRNA-binding activity and structures similar to those containing S12WT, the $\Delta r p s L \mathrm{pS} 12 \Delta 11 \mathrm{~N}$ strain exhibits growth defects and an aberrant subunit profile. The differences between in vivo SSU biogenesis and in vitro reconstitution of SSUs or minimal $16 \mathrm{~S}$ rRNA-containing particles could account for the observed differences. Notably, there is an increase in pre-16S rRNA in the $\triangle r p s L \mathrm{pS} 12 \Delta 11 \mathrm{~N}$ strain, thus suggesting that elements of the in vivo biogenesis cascade are influenced by this truncation and this involvement would not be evident in our in vitro experiments. Additionally, the 11th residue of $\mathrm{S} 12$ is an arginine, and mutation of this residue has previously been implicated in changes in SSU function in vivo (Agarwal et al. 2011). In fact, this is also consistent with data from in vitro structural analysis of particles incorporat- ing $\mathrm{S} 12 \Delta 15 \mathrm{~N}$; in which protection at nucleotide 563 , in direct contact with R11 in the X-ray crystal structure is lost. Thus, the observed importance of this residue in SSU function and biogenesis would be consistent with our data.

These observations suggest a model for the role of the noncanonically structured region of S12 in SSU biogenesis. Deletion of the extension results in structural perturbations of the platform of $16 \mathrm{~S}$ rRNA in vitro, suggesting that the extension may be important in the architecture of this region of the assembled SSU (Figs. 3, 6). Previous in vitro studies suggest that stabilization of $16 \mathrm{~S}$ rRNA architecture in the platform occurs late in SSU assembly (Talkington et al. 2005; Adilakshmi et al. 2008), and this work supports such a role for the S12 N-terminal extension in scaffolding $16 \mathrm{~S}$ rRNA structure.

Roles for the extended loops and unstructured regions of $\mathrm{r}$ proteins have been the subject of speculation, but little is known of their function in assembly and translation (see Ban et al. 2000; Wimberly et al. 2000; Wilson and Nierhaus 2005; Timsit et al. 2009). One hypothesis is that r-proteins with long extensions represent a subset of intrinsically disordered proteins whose function depends upon a structural transition from a disordered form to an ordered structure upon the binding of its partner (Uversky et al. 2000; Iakoucheva et al. 2002; Timsit et al. 2009). For example, the $\mathrm{N}$-terminal extension of r-protein L20 undergoes a helix-coil transition upon binding $23 \mathrm{~S}$ rRNA, and is essential for large subunit assembly (Guillier et al. 2005; Timsit et al. 2006). Similar data for $S 4$ in the in vitro assembly of the $30 \mathrm{~S}$ subunit also lend credence to the idea that $\mathrm{r}$-proteins with long noncanonically structured regions play an important role in assembly by cofolding with 16S rRNA (Mayerle and Woodson 2013). Our study suggests that the N-terminal extension of S12 also plays a role in stabilizing SSU structure during biogenesis.

\section{MATERIALS AND METHODS}

\section{Plasmids}

Primers introducing a translation initiation codon at desired sites within $r p s L$ were utilized for PCR amplification from MG1655 genomic DNA to generate full-length and truncation variants of S12. The truncations are designated by $\mathrm{S} 12 \Delta \mathrm{XN}$, where $\mathrm{X}$ signifies the number of truncated residues, while $\mathrm{N}$ indicates that the protein has been truncated at the N-terminus. C-terminal His-tagged versions of S12 were expressed and purified for use in vitro. Full-length and truncated variants $(\Delta 10 \mathrm{~N}, \Delta 15 \mathrm{~N}$, and $\Delta 27 \mathrm{~N})$ of S12 were cloned into the NdeI and HindIII sites of pET24 (Novagen, kanamycin resistant) without a stop codon at the C-terminus of the gene. S12WT, which is the full-length untagged protein cloned in pET21b is a gift from the laboratory of Dr. Noller.

The str operon including the genes $r p s L, r p s G$, fusA, and tufA was cloned into the NotI site of pKOV to generate pSTR. pKOV expresses $s a c B$, a gene that causes the loss of the host plasmid in the presence of sucrose (Link et al. 1997). Primers introducing a translation 
initiation codon at desired sites within $r p s L$ were utilized for PCR amplification from MG1655 genomic DNA to generate full-length and truncation variants of S12. The wild-type (S12WT) and truncated $(\mathrm{S} 12 \Delta 6 \mathrm{~N}, \mathrm{~S} 12 \Delta 11 \mathrm{~N}, \mathrm{~S} 12 \Delta 15 \mathrm{~N}$, and $\mathrm{S} 12 \Delta 24 \mathrm{~N}) r p s$ genes were cloned into the NcoI and HindIII sites of pBAD HisB (Invitrogen, ampicillin resistant) with a C-terminal stop codon, to express untagged protein in vivo. The protein was truncated at a different set of residues due to the constraints of restriction enzyme choice.

\section{Purification of proteins}

Strains expressing S12WT from pET21b and S12Full Length, $\mathrm{S} 12 \Delta 10 \mathrm{~N}, \mathrm{~S} 12 \Delta 15 \mathrm{~N}$, and $\mathrm{S} 12 \Delta 27 \mathrm{~N}$ from pET24 were grown to $\mathrm{OD}_{600}=0.7$, then induced with $1 \mathrm{mM}$ IPTG for $3 \mathrm{~h}$. The cells were pelleted at $7000 \mathrm{rpm}$ for $10 \mathrm{~min}$, then lysed in Buffer E (20 $\mathrm{mM} \mathrm{K}{ }^{+}$-HEPES at $\mathrm{pH} 7.6,20 \mathrm{mM} \mathrm{KCl}$, and $6 \mathrm{mM} \beta \mathrm{ME}$ ) in an Avestin Emulsiflex-C3 cell lyser. The lysate was cleared by spinning at $10,000 \mathrm{rpm}$ in a JA-17 rotor in a Beckman high-speed centrifuge for $5 \mathrm{~min}$ at $4^{\circ} \mathrm{C}$.

S12WT supernatant was dialyzed overnight into Buffer B (20 mM sodium acetate at $\mathrm{pH} 5.6,20 \mathrm{mM} \mathrm{KCl}, 6 \mathrm{M}$ urea, and $6 \mathrm{mM} \beta \mathrm{ME}$ ). Proteins were purified by fast protein liquid chromatography using a Resource-S cation exchange column (GE) and eluted with a 35-mL salt gradient from 100 to $350 \mathrm{mM} \mathrm{KCl}$ in Buffer C (20 mM sodium acetate at $\mathrm{pH} 5.6,1 \mathrm{M} \mathrm{KCl}, 6 \mathrm{M}$ urea, and $6 \mathrm{mM} \beta \mathrm{ME}$ ). The proteins were eluted at $\sim 230 \mathrm{mM} \mathrm{KCl}$. Purified proteins were dialyzed into Buffer D $\left(80 \mathrm{mM} \mathrm{K}^{+}\right.$-HEPES at $\mathrm{pH} 7.6,1 \mathrm{M} \mathrm{KCl}$, and $6 \mathrm{mM}$ $\beta \mathrm{ME})$, aliquoted, and frozen in liquid nitrogen.

S12 $\triangle \mathrm{XN}$ and S12Full Length pellets were resuspended in Buffer $\mathrm{BH}(100 \mathrm{mM}$ sodium dihydrogen phosphate, $330 \mathrm{mM} \mathrm{KCl}, 6 \mathrm{M}$ urea, $20 \mathrm{mM}$ Imidazole, $6 \mathrm{mM} \beta \mathrm{ME}$ at $\mathrm{pH}$ 7.4) by rocking the pellet overnight at $4^{\circ} \mathrm{C}$. The solution was cleared at $7000 \mathrm{rpm}$ for $20 \mathrm{~min}$, twice, before loading sample for affinity purification on a HiTrap Chelating HP column (GE). The column was washed with Buffer $\mathrm{CH}$ (100 mM sodium dihydrogen phosphate, $330 \mathrm{mM} \mathrm{KCl,} 6 \mathrm{M}$ urea, $50 \mathrm{mM}$ imidazole, $6 \mathrm{mM} \beta \mathrm{ME}$ at $\mathrm{pH}$ 7.4). The proteins were eluted by a gradient of from $125 \mathrm{mM}$ to $250 \mathrm{mM}$ Imidazole in 20 $\mathrm{mL}$ Buffer $\mathrm{EH}$ (100 mM sodium dihydrogen phosphate, $330 \mathrm{mM}$ $\mathrm{KCl}, 6 \mathrm{M}$ Urea, $250 \mathrm{mM}$ imidazole, $6 \mathrm{mM} \beta \mathrm{ME}$ at $\mathrm{pH}$ 7.4). The proteins eluted at $\sim 163 \mathrm{mM}$ imidazole concentration. The proteins were step dialyzed with gradations of $0.5 \mathrm{M}$ urea and $50 \mathrm{mM}$ imidazole into Buffer DH (80 $\mathrm{mM} \mathrm{K}^{+}$-HEPES at $\mathrm{pH} 7.6,1 \mathrm{M} \mathrm{KCl}, 3 \mathrm{M}$ urea, and $6 \mathrm{mM} \beta \mathrm{ME}$ ), aliquoted, and stored in liquid nitrogen.

\section{Assembly of ribonucleoprotein particles in vitro}

$16 \mathrm{~S}$ rRNA was isolated as described (Moazed et al. 1986), heat activated by incubating at $42^{\circ} \mathrm{C}$ for $15 \mathrm{~min}$ in Buffer A $\left(80 \mathrm{mM} \mathrm{K}^{+}\right.$Hepes at $\mathrm{pH} 7.6,330 \mathrm{mM} \mathrm{KCl}, 20 \mathrm{mM} \mathrm{MgCl}_{2}$, and $0.01 \%$ Nikkol), and then incubated on ice for $10 \mathrm{~min}$. Ribonucleoprotein particles were reconstituted essentially as described (Culver and Noller 2000) except that the reconstitution was carried out in the presence of $30 \mathrm{mM}$ urea. $30 \mathrm{~S}$ particles were formed by mixing 280 pmol of any variant of S12 (wild-type, full-length, $\Delta 10, \Delta 15$, or $\Delta 27$ ) with $240 \mathrm{pmol}$ of total r-protein mix (all r-proteins except S12) and 40 pmol of $16 \mathrm{~S}$ rRNA in a final volume of $100 \mu \mathrm{L}$ with a final $\mathrm{KCl}$ concentration of $330 \mathrm{mM}$. In minimal particles, 240 pmol of minimal r-protein mix (S4, S7, S8, S15, S16, S17, and S20) was substituted for total r-protein mix. In order to form the
RNPs, the reactions were incubated at $42^{\circ} \mathrm{C}$ for $20 \mathrm{~min}$. These were then cooled on ice for $10 \mathrm{~min}$ before proceeding to the next experiment.

\section{In vitro transfer RNA (tRNA) binding}

A poly-U-dependent tRNA-binding experiment was performed essentially as described (Culver and Noller 1999) with a saturating excess of tRNA such that the assay monitored factor-independent, multi-site tRNA-binding activity of the SSU. The assay was carried out in the presence of $30 \mathrm{mM}$ urea. The results presented are from three independent experiments.

\section{Chemical probing of RNP conformation}

Chemical probing of the minimal RNPs by dimethyl sulfate was carried out essentially as described (Moazed et al. 1986). The complexes were assembled, chilled on ice for $10 \mathrm{~min}$, and then treated with dimethyl sulfate at a final concentration of $33.8 \mathrm{mM}$ and incubated for $1 \mathrm{~h}$ on ice. The reactions were visualized by primer extension as described (Moazed et al. 1986) using primers initiating cDNA synthesis at nucleotides 232,683 , and 1046. Results are representative of three independent experiments.

\section{Generation of $E$. coli strains}

A strain lacking a genomic copy of $\mathrm{S} 12$ (S12koBW) was created by Sharma et al. (2007). It was used as a donor strain in P1 transduction experiments to replace the $r p s L$ gene in the strain MG1655str with a kanamycin resistance marker, generating $\Delta r p s l$ pSTR. $\Delta r p s l$ pSTR is temperature and sucrose sensitive. It was transformed with $\mathrm{pBAD}$ expressing WT and $\triangle \mathrm{X} r p s l$ and the transformants grown overnight in $5 \mathrm{~mL}$ of LB. The overnight culture was then plated on LB agar plates containing kanamycin $(50 \mu \mathrm{g} / \mathrm{mL})$, ampicillin $(100 \mu \mathrm{g} / \mathrm{mL})$, arabinose $(2 \%)$, and sucrose $(5 \%)$ to replace pSTR with pS12, generating $\Delta r p s L \mathrm{pS} 12 \mathrm{WT}, \Delta r p s L \mathrm{pS} 12 \Delta 6 \mathrm{~N}, \Delta r p s L \mathrm{pS} 12 \Delta 11 \mathrm{~N}$, and $\Delta r p s L \mathrm{pS} 12 \Delta 15 \mathrm{~N}$. In order to avoid picking suppressors or revertants, slow growing $(\approx 48 \mathrm{~h})$ colonies expressing truncated forms of S12 were chosen for further analysis. The presence of compensatory mutations in the strains dependent on truncated proteins cannot be ruled out, but their slow growth phenotype leads us to believe that this is unlikely.

\section{Analysis of growth properties}

All overnight cultures were grown at $37^{\circ} \mathrm{C}$ in the presence of kanamycin $(50 \mu \mathrm{g} / \mathrm{mL})$, ampicillin $(100 \mu \mathrm{g} / \mathrm{mL})$, and arabinose $(0.2 \%)$ with shaking (200 rpm). For growth on solid media, overnight cultures were diluted to $\mathrm{OD}_{600}=0.6$, then serially diluted by a factor of 10. The dilutions were spotted on LB-agar plates containing kanamycin $(50 \mu \mathrm{g} / \mathrm{mL})$, ampicillin $(100 \mu \mathrm{g} / \mathrm{mL})$, and arabinose $(0.2 \%)$ and the plates incubated at $37^{\circ} \mathrm{C}$ and $25^{\circ} \mathrm{C}$ to examine growth at optimal and nonpermissive temperatures.

Growth curves at $37^{\circ} \mathrm{C}$ were obtained by two methods. In one method overnight cultures were diluted to equal $\mathrm{OD}_{600}$ in $50 \mathrm{~mL}$ $\mathrm{LB}$ media and the $\mathrm{OD}_{600}$ was determined from aliquots taken at 30-min intervals. In the second technique, two overnight cultures of each strain were diluted to equal $\mathrm{OD}_{600}$ in $200 \mu \mathrm{L}$ of media in a 
microtiter plate. This was replicated in five wells for each overnight culture. The plates were grown in a Bioscreen automatic growth analyzer with shaking to periods of $20 \mathrm{sec}$ of maximum intensity per minute. Growth was monitored at the wideband setting every 20 min (Weichart and Kell 2001). The data were collected during a single run of a plate at $37^{\circ} \mathrm{C}$. Growth in microtiter plates yielded longer doubling times than growth in flasks for each strain. However, there was no significant difference in the ratio of the doubling time of mutants to wild-type strains, therefore only data from five independent growths within the Bioscreen analyzer are presented.

\section{Analysis of ribosome sedimentation profiles}

All of the strains were inoculated to equal $\mathrm{OD}_{600}$ in $500 \mathrm{~mL}$ LB. All strains were grown to an $\mathrm{OD}_{600}$ of 0.6 or for a maximum of $8 \mathrm{~h}$. The cells were treated as described (Connolly et al. 2008) to obtain subunit profiles. The data are derived from four independent growths. The area under the peak for each profile was calculated using the program QTiPlot. Ribosome containing peak intensity was corrected to represent only SSUs as in Connolly et al. (2008). Data are representative of three independent experiments.

\section{Analysis of rRNA from SSUs and ribosomes}

SSUs and ribosomes were collected after sucrose gradient centrifugation of cell lysate. RNA was extracted as described in Culver and Noller (2000), and analyzed by agarose gel electrophoresis. Data are representative of two independent experiments.

\section{ACKNOWLEDGMENTS}

The donor strain for P1 transduction, S12koBW, was a gift from Dr. Rachel Green. We thank Drs. George Church for pKOV plasmids, Scott Butler and David Goldfarb and their laboratories for help with equipment and materials, and Drs. Elaine Sia and Martin Pavelka as well as their laboratories for technical advice.

Received September 11, 2013; accepted November 21, 2013.

\section{REFERENCES}

Adilakshmi T, Bellur DL, Woodson SA. 2008. Concurrent nucleation of $16 \mathrm{~S}$ folding and induced fit in $30 \mathrm{~S}$ ribosome assembly. Nature 455: $1268-1272$.

Agarwal D, Gregory ST, O'Connor M. 2011. Error-prone and error-restrictive mutations affecting ribosomal protein S12. J Mol Biol 410: $1-9$.

Alksne LE, Anthony RA, Liebman SW, Warner JR. 1993. An accuracy center in the ribosome conserved over 2 billion years. Proc Natl Acad Sci 90: 9538-9541.

Allers J, Shamoo Y. 2001. Structure-based analysis of protein-RNA interactions using the program ENTANGLE. J Mol Biol 311: 75-86.

Ban N, Nissen P, Hansen J, Moore PB, Steitz TA. 2000. The complete atomic structure of the large ribosomal subunit at $2.4 \AA$ resolution. Science 289: 905-920.

Ben-Shem A, Jenner L, Yusupova G, Yusupov M. 2010. Crystal structure of the eukaryotic ribosome. Science 330: 1203-1209.

Brodersen DE, Clemons WM Jr, Carter AP, Wimberly BT, Ramakrishnan V. 2002. Crystal structure of the 30S ribosomal subunit from Thermus thermophilus: Structure of the proteins and their interactions with 16S RNA. J Mol Biol 316: 725-768.
Calidas D, Culver GM. 2011. Interdependencies govern multidomain architecture in ribosomal small subunit assembly. RNA 17: 263-277.

Campbell TL, Brown ED. 2008. Genetic interaction screens with ordered overexpression and deletion clone sets implicate the Escherichia coli GTPase YjeQ in late ribosome biogenesis. J Bacteriol 190: 2537-2545.

Clemons WM Jr, May JL, Wimberly BT, McCutcheon JP, Capel MS, Ramakrishnan V. 1999. Structure of a bacterial 30S ribosomal subunit at $5.5 \AA$ resolution. Nature 400: 833-840.

Connolly K, Rife JP, Culver G. 2008. Mechanistic insight into the ribosome biogenesis functions of the ancient protein KsgA. Mol Microbiol 70: 1062-1075.

Culver GM, Noller HF. 1999. Efficient reconstitution of functional Escherichia coli 30 S ribosomal subunits from a complete set of recombinant small subunit ribosomal proteins. RNA 5: 832-843.

Culver GM, Noller HF. 2000. In vitro reconstitution of 30 S ribosomal subunits using complete set of recombinant proteins. Methods Enzymol 318: 446-460.

Gorini L, Kataja E. 1964a. Phenotypic repair by streptomycin of defective genotypes in E. coli. Proc Natl Acad Sci 51: 487-493.

Gorini L, Kataja E. 1964b. Streptomycin-induced oversuppression in E. coli. Proc Natl Acad Sci 51: 995-1001.

Guillier M, Allemand F, Graffe M, Raibaud S, Dardel F, Springer M, Chiaruttini C. 2005. The N-terminal extension of Escherichia coli ribosomal protein L20 is important for ribosome assembly, but dispensable for translational feedback control. RNA 11: 728-738.

Iakoucheva LM, Brown CJ, Lawson JD, Obradovic Z, Dunker AK. 2002. Intrinsic disorder in cell-signaling and cancer-associated proteins. J Mol Biol 323: 573-584.

Inoue K, Alsina J, Chen J, Inouye M. 2003. Suppression of defective ribosome assembly in a rbfA deletion mutant by overexpression of Era, an essential GTPase in Escherichia coli. Mol Microbiol 48: $1005-1016$.

Jakovljevic J, de Mayolo PA, Miles TD, Nguyen TM, Leger-Silvestre I, Gas N, Woolford JL Jr. 2004. The carboxy-terminal extension of yeast ribosomal protein S14 is necessary for maturation of $43 \mathrm{~S}$ preribosomes. Mol Cell 14: 331-342.

Lee K, Varma S, SantaLucia J Jr, Cunningham PR. 1997. In vivo determination of RNA structure-function relationships: Analysis of the 790 loop in ribosomal RNA. J Mol Biol 269: 732-743.

Link AJ, Phillips D, Church GM. 1997. Methods for generating precise deletions and insertions in the genome of wild-type Escherichia coli: Application to open reading frame characterization. J Bacteriol 179: 6228-6237.

Lodmell JS, Dahlberg AE. 1997. A conformational switch in Escherichia coli $16 \mathrm{~S}$ ribosomal RNA during decoding of messenger RNA. Science 277: 1262-1267.

Mayerle M, Woodson SA. 2013. Specific contacts between protein S4 and ribosomal RNA are required at multiple stages of ribosome assembly. RNA 19: 574-585.

Moazed D, Noller HF. 1990. Binding of tRNA to the ribosomal A and P sites protects two distinct sets of nucleotides in 16S rRNA. J Mol Biol 211: 135-145.

Moazed D, Stern S, Noller HF. 1986. Rapid chemical probing of conformation in 16 S ribosomal RNA and 30S ribosomal subunits using primer extension. J Mol Biol 187: 399-416.

Ogle JM, Murphy FV, Tarry MJ, Ramakrishnan V. 2002. Selection of tRNA by the ribosome requires a transition from an open to a closed form. Cell 111: 721-732.

Powers T, Noller HF. 1991. A functional pseudoknot in $16 \mathrm{~S}$ ribosomal RNA. EMBO J 10: 2203-2214.

Powers T, Noller HF. 1995. Hydroxyl radical footprinting of ribosomal proteins on 16S rRNA. RNA 1: 194-209.

Schuwirth BS, Borovinskaya MA, Hau CW, Zhang W, Vila-Sanjurjo A, Holton JM, Cate JH. 2005. Structures of the bacterial ribosome at 3.5 Å resolution. Science 310: 827-834.

Sharma D, Cukras AR, Rogers EJ, Southworth DR, Green R. 2007. Mutational analysis of $\mathrm{S} 12$ protein and implications for the accuracy of decoding by the ribosome. J Mol Biol 374: 1065-1076. 
Shoji S, Dambacher CM, Shajani Z, Williamson JR, Schultz PG. 2011. Systematic chromosomal deletion of bacterial ribosomal protein genes. J Mol Biol 413: 751-761.

Smith TF, Lee JC, Gutell RR, Hartman H. 2008. The origin and evolution of the ribosome. Biol Direct 3: 16.

Stern S, Changchien LM, Craven GR, Noller HF. 1988a. Interaction of proteins S16, S17 and S20 with 16 S ribosomal RNA. J Mol Biol 200: 291-299.

Stern S, Powers T, Changchien LM, Noller HF. 1988b. Interaction of ribosomal proteins S5, S6, S11, S12, S18 and S21 with 16S rRNA. J Mol Biol 201: 683-695.

Svensson P, Changchien LM, Craven GR, Noller HF. 1988. Interaction of ribosomal proteins, S6, S8, S15 and S18 with the central domain of 16 S ribosomal RNA. J Mol Biol 200: 301-308.

Talkington MW, Siuzdak G, Williamson JR. 2005. An assembly landscape for the 30S ribosomal subunit. Nature 438: 628-632.

Timsit Y, Allemand F, Chiaruttini C, Springer M. 2006. Coexistence of two protein folding states in the crystal structure of ribosomal protein L20. EMBO Rep 7: 1013-1018.

Timsit Y, Acosta Z, Allemand F, Chiaruttini C, Springer M. 2009. The role of disordered ribosomal protein extensions in the early steps of eubacterial 50 S ribosomal subunit assembly. Int J Mol Sci 10: $817-834$.
Uversky VN, Gillespie JR, Fink AL. 2000. Why are "natively unfolded" proteins unstructured under physiologic conditions? Proteins 41: 415-427.

Weichart DH, Kell DB. 2001. Characterization of an autostimulatory substance produced by Escherichia coli. Microbiology 147: 18751885 .

Wilson DN, Nierhaus KH. 2005. Ribosomal proteins in the spotlight. Crit Rev Biochem Mol Biol 40: 243-267.

Wimberly BT, Brodersen DE, Clemons WM Jr, Morgan-Warren RJ, Carter AP, Vonrhein C, Hartsch T, Ramakrishnan V. 2000. Structure of the 30S ribosomal subunit. Nature 407: 327-339.

Woese CR, Magrum LJ, Gupta R, Siegel RB, Stahl DA, Kop J, Crawford N, Brosius J, Gutell R, Hogan JJ, et al. 1980. Secondary structure model for bacterial $16 \mathrm{~S}$ ribosomal RNA: Phylogenetic, enzymatic and chemical evidence. Nucleic Acids Res 8: 2275-2293.

Yusupov MM, Yusupova GZ, Baucom A, Lieberman K, Earnest TN, Cate JH, Noller HF. 2001. Crystal structure of the ribosome at 5.5 Å resolution. Science 292: 883-896.

Zengel JM, Jerauld A, Walker A, Wahl MC, Lindahl L. 2003. The extended loops of ribosomal proteins L4 and L22 are not required for ribosome assembly or L4-mediated autogenous control. RNA 9: 1188-1197.

Zhang R, Lin Y. 2009. DEG 5.0, a database of essential genes in both prokaryotes and eukaryotes. Nucleic Acids Res 37: D455-D458. 

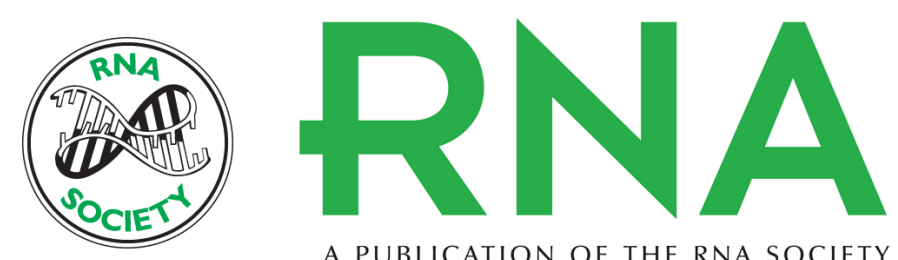

A PUBLICATION OF THE RNA SOCIETY

\section{The N-terminal extension of S12 influences small ribosomal subunit assembly in Escherichia coli}

Deepika Calidas, Hiram Lyon and Gloria M. Culver

RNA 2014 20: 321-330 originally published online January 17, 2014

Access the most recent version at doi:10.1261/rna.042432.113

\section{References This article cites 46 articles, 17 of which can be accessed free at: http://rnajournal.cshlp.org/content/20/3/321.full.html\#ref-list-1}

Creative This article is distributed exclusively by the RNA Society for the first 12 months after the Commons full-issue publication date (see http://rnajournal.cshlp.org/site/misc/terms.xhtml). After 12 License months, it is available under a Creative Commons License (Attribution-NonCommercial 3.0 Unported), as described at http://creativecommons.org/licenses/by-nc/3.0/.

Email Alerting Receive free email alerts when new articles cite this article - sign up in the box at the Service top right corner of the article or click here.

\section{||||||| Providing Precise Solutions for your research.}

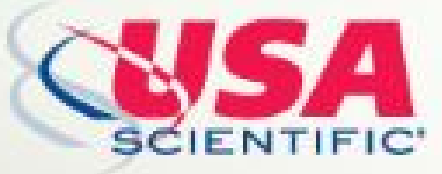

To subscribe to $R N A$ go to:

http://rnajournal.cshlp.org/subscriptions 